RESEARCH PAPER RP718

Part of Journal of Research of the National Bureau of Standards, Volume 13
October 1934

\title{
STANDARDIZATION OF LOVIBOND RED GLASSES IN COMBINATION WITH LOVIBOND 35 YELLOW 1
}

\author{
By Kasson S. Gibson and Geraldine Walker Haupt
}

\section{ABSTRACT}

Inconsistencies in the grades of Lovibond red glasses have long been a source of annoyance and dispute among oil chemists, who use these glasses in the color grading of vegetable oils. Thousands of such glasses are in use in this country, over 2,300 of them having now been submitted to the Bureau for renumbering. A statistical investigation has been made of the uniformity of grades of the first 1,000 glasses and the results recently published in NBS Research Pap. RP653.

The present paper describes the fundamental standardization of the Bureau's Lovibond red glasses, with which these 2,300 glasses have been compared and in terms of which they have been renumbered. The purpose of the standardization was to derive new numerals for the Bureau glasses, approximately equal in magnitude to the original numerals but free from certain inconsistencies occurring among them. The standardization is based upon spectrophotometric analyses of the glasses when in combination with Lovibond 35 yellow. The new numerals were derived from colorimetric computations based on the spectral transmission data, and they are shown to be on a consistent additive scale. This scale covers a range from yellow to yellowish-red. Tolerances of colorimetric purity and light transmission are considered.

\section{CONTENTS}

I. Introduction

Page

II. Derivation of the Priest-Gibson $\left(N^{\prime}\right)$ scale and unit.

1. Derivation and test of the $N^{\prime}$ numerals

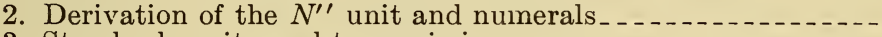

3. Standard purity and transmission curves

4. Selection of standards for routine calibration of Lovibond red glasses

III. Experimental tests of additivity of the $N^{\prime \prime}$ scale

IV. Comparison of $N^{\prime \prime}$ values obtained via spectral transmission and computation of $r / g$, and via direct comparison with the standards -

V. Revision of the $\left(r / g, N^{\prime \prime}\right)$ standard curve 442

VI. Representative nature of the $N^{\prime \prime}$ unit and scale Appendix. Effect of spectrophotometric uncertainties. 449

\section{INTRODUCTION}

The present paper is one of several ${ }^{2}$ that have been published in recent years by members of the Bureau staff dealing with the meas-

1 Credit for secs. II and III of this paper is due in large part to the late Irwin G. Priest, Chief of the Color imetry Section 1913-32, under whose direction the Lovibond glass standardization program has been performed. The urgency of other work prevented Mr. Priest from preparing the material of these sections for publication, and in March 1931 he requested the authors to prepare the present paper, but without himself as author.

2 K. S. Gibson, F. K. Harris, and I. G. Priest, The Lovibond color system-A spectrophotometric analysis of the Lovibond glasses, BS Sci. Pap. 22,1(1927-28);S547. D. B. Judd and G. K. Walker, A study of 129 Lovibond red glasses with respect to the reliability of their nominal grades, Oil and Fat Industries $\mathbf{5 , 1 6 ( 1 9 2 8 )}$ I. G. Priest, Tests of color sense of A.O.C.S. members and data on sensibility to change in Lovibond red, Oil and Fat Industries 5,63(1928). D. B. Judd, Effect of temperature change on the color of red and yellow Lovibond glasses, BS J. Research 1,859(1928);R P31. I. G. Priest, D. B. Judd, K. S. Gibson, and G. K. Walker, Calibration of sixty-five 35-yellow Lovibond glasses, BS J.Research $\pi, 793(1929)$;RP58. G. K. Walker, Statistical investigation of the uniformity of grades of 1,000 Lovibond red glasses, BS J.Research 12,269(1934); RP653. 
urement and calibration of Lovibond glasses. It describes primarily the method used in standardizing the Lovibond red glasses belonging to the National Bureau of Standards (those having BS inventory number 9940). Thousands of Lovibond red glasses are in use in this country, over 2,300 of them having been submitted to the Bureau since 1927 for calibration in terms of the Bureau's glasses. ${ }^{3}$

This standardization was carried out at the insistence of those who use such glasses in the grading of vegetable oils. ${ }^{4}$ The nature of the standardization was dictated by the following considerations:

1. The glasses of set BS 9940 had previously been accepted as "standard" by the Interstate Cotton Seed Crushers' Association, and by the Society of Cotton Products Analysts (now American Oil Chemists' Society). ${ }^{5}$

2. The set had to be standardized within itself; there was no other standard set with which to compare it.

3. The standardization must be based upon fundamental absolute measurements; it must not be dependent upon the permanence of the glasses or of any other material color "standards."

4. The numbers assigned to the glasses when standardized must be additive ${ }^{B}$ within prescribed tolerances.

5. The glasses must be combined with some prescribed yellow glass. Because of the color of vegetable oils, the red ${ }^{7}$ glasses are always used in combination with Lovibond yellow glasses, ${ }^{8}$ and in decisions of greatest importance in combination with a 35-yellow glass. ${ }^{9}$ The standardization described in this paper has been carried out, therefore, with the respective red glasses combined with a $35-$ yellow glass. The values obtained are doubtless valid for a considerable range of yellow glasses on both sides of $35 \mathrm{Y}$; but the values do not necessarily hold for the red glasses used alone or with a Lovibond yellow glass of small numeral.

\section{DERIVATION OF THE PRIEST-GIBSON ( $\left.N^{\prime \prime}\right)$ SCALE AND UNIT}

\section{DERIVATION AND TEST OF THE $N^{\prime}$ NUMERALS}

To comply with requirement 3 above, the new numerals assigned the glasses must necessarily be derived from their spectral transmissions. The values of spectral transmission for the glasses,

\footnotetext{
3 Results obtained on the first 1,000 glasses have been published in BS Research Pap. RP653.

4 See prefatory statement in BS Sci. Pap. S547.

5 Proc. Fourth Annual Meeting, Soc. Cotton Products Analysts, pp. 6 and 12, Chicago, June 21, 1913. See also BS Sci. Pap. S547, p.6.

6 The additivity condition has been expressed (J.O.S.A. \& R.S.I., 16,116; February 1928) as
}

$$
(\Sigma N)_{1}=(\Sigma N)_{2}
$$

where $(\Sigma N)_{1}$ and $(\Sigma N)_{2}$ are the sums of the scale numerals attached respectively to 2 combinations of glasses such that: (1) They contain equal numbers of glasses (nonselective glass of nearly zero absorption being introduced if needed), and (2) they evoke the same color under like conditions. This is the most general case, color being understood in its threefold meaning of hue, saturation, and brilliance. Standardization of the desired type and precision cannot be obtained, however, unless the brilliance of the color is eliminated from consideration. This has accordingly been done (1) in the standardization of the Bureau's glasses (set BS 9940), by giving no weight to the luminous transmission of the glasses in the assignment of the new $\left(N^{\prime \prime}\right)$ numerals, as is explained later, and (2) in the grading of glasses submitted for calibration, by use of the Martens photometer for comparing the test glass with the standards, the criterion for equality being a chromaticity match (hue and saturation only) and the brightnesses of the 2 parts of the photometric field being independently equated by the observer. (See BS Research Pap. RP653.) In such direct comparisons of glasses, also, the maximum number allowed in either beam is 3 . Throughout the present paper the term additivity is to be understood as referring to chromaticity rather than color.

"The "red" Lovibond glasses are of nonspectral hue, having spectral transmissions of the "gold-ruby" type, in which the principal absorption occurs in the green. (See BS Sci. Pap. S547, fig. 1.)

s See, for example, the Report of Color Committee of the American Oil Chemists' Society, Year 1932-83, Oil and Soap, 10, 114 (June 1933).

9 Rules governing transactions between members of the National Cottonseed Products Association, Ine. (See article 4, rules $60-65$.) 
$N^{10}=1.0,2.0,3.0 \ldots 20.0$, were used as published in BS Sci. Pap. S547, p. 25, table 1. To comply with requirement 5 of the previous section, the various spectral transmissions were multiplied wave length by wave length by the spectral transmission of a 35-yellow glass. The particular glass used for this purpose was one submitted under test number 41,960 ; its spectral transmission has been published. ${ }^{11}$

The combination, 35 yellow with variable red, gives a scale varying from yellow to red. This change of hue may be represented by several parameters, the most suitable of which for standardization purposes has proven to be the ratio of the red to the green trilinear coordinates, ${ }^{12} \mathrm{r} / \mathrm{g}$.

The trilinear coordinates, $r, g, b$, were computed for each of the 20 glasses $(N=1.0,2.0 \ldots \ldots 20.0)$ of BS 9940 in combination with $35 \mathrm{Y}$ of BS test 41960 . Plotting values of $r / g$ against values of $N$ gave the results shown in figure 1. A study of these data indicated that, on the average, they could be represented by a quadratic equation with suitably chosen constants. The equation

$$
r / g=a+b N+c N^{2}
$$

was, therefore, assumed, in which $a$ has the value of. $r / g$ for the $35 \mathrm{Y}$ glass alone $(N=0)$. Values of the constants $b$ and $c$ were obtained from a least-squares adjustment of the data. The 3 values are as follows:

$$
\begin{aligned}
& a=1.0958 \\
& b=0.066865 \\
& c=0.00031897
\end{aligned}
$$

A new series of values for these glasses was obtained by inserting values of $r / g$ in the equation and computing new values for $N$, which were designated $N^{\prime}$. Graphically, $N^{\prime}$ is, of course, the value read from the curve of figure 1 corresponding to a given value of $r / g$.

The irregular variations of the $N$ scale for the red glasses of BS 9940 with $35 \mathrm{Y}$, shown by the deviations of the plotted points from the curve in figure 1 , have been in the more extreme cases well known for many

${ }_{10}$ Throughout the rest of the paper the symbol $N$ refers to the numerals engraved on the glasses as received from the Lovibond establishment.

${ }_{11}$ BS Sci. pap. S547, table 6, p. 30 . Figure 9 of that paper gives spectral transmission curves of the red glasses of BS $9940, N=1.0$ to 20.0 , in combination with a 35 -yellow glass.

12 The constants used in computing the trilinear coordinates of the Lovibond glasses are as given in table 1 , p. 525, of BS Research Pap. RP163. (Deane B. Judd, Reduction of data on mixture of color stimuli, BS J.Research (April 1930).) The values of $\rho_{1}, \gamma_{1}$, and $\beta_{1}$ there given represent the distributions of the "O.S.A. excitations" (extrapolated) throughout the spectrum of Abbot-Priest sunlight. If $T$ represent the spectral transmission of a glass or combination of glasses, $r, g$, and $b$ are defined and computed as:

$$
\begin{aligned}
& r=\frac{\Sigma \rho_{1} T}{\Sigma \rho_{1} T+\Sigma \gamma_{1} T+\Sigma \beta_{1} T}, \\
& g=\frac{\Sigma \gamma_{1} T}{\Sigma \rho_{1} T+\Sigma \gamma_{1} T+\Sigma \beta_{1} T}, \\
& b=\frac{\Sigma \beta_{1} T}{\Sigma \rho_{1} T+\Sigma \gamma_{1} T+\Sigma \beta_{1} T},
\end{aligned}
$$

the summations being taken at every $10 \mathrm{~m} \mu$ from 380 to $720 \mathrm{~m} \mu$.

From this it is apparent that $r / g=\frac{\Sigma \rho_{1} T}{\Sigma \gamma_{1} T}$. The values of $b$ do not enter into the computation of $r / g$ but are used in computing the colorimetric purity, as described later. 
years, being thoroughly established by various preliminary calibrations of one sort or another. ${ }^{13}$

The $N^{\prime}$ scale, derived by the least-squares adjustment just described, represents the average Lovibond red scale (when in combination with $35 \mathrm{Y}$ ) as established from the numerals engraved on the glasses by the Tintometer, Ltd., insofar as the 20 red glasses of BS 9940 used in its derivation represent the average of all Lovibond red glasses of like denomination in existence. The degree to which these 20 glasses represent the average of all the Lovibond red glasses so far examined is discussed in section VI.

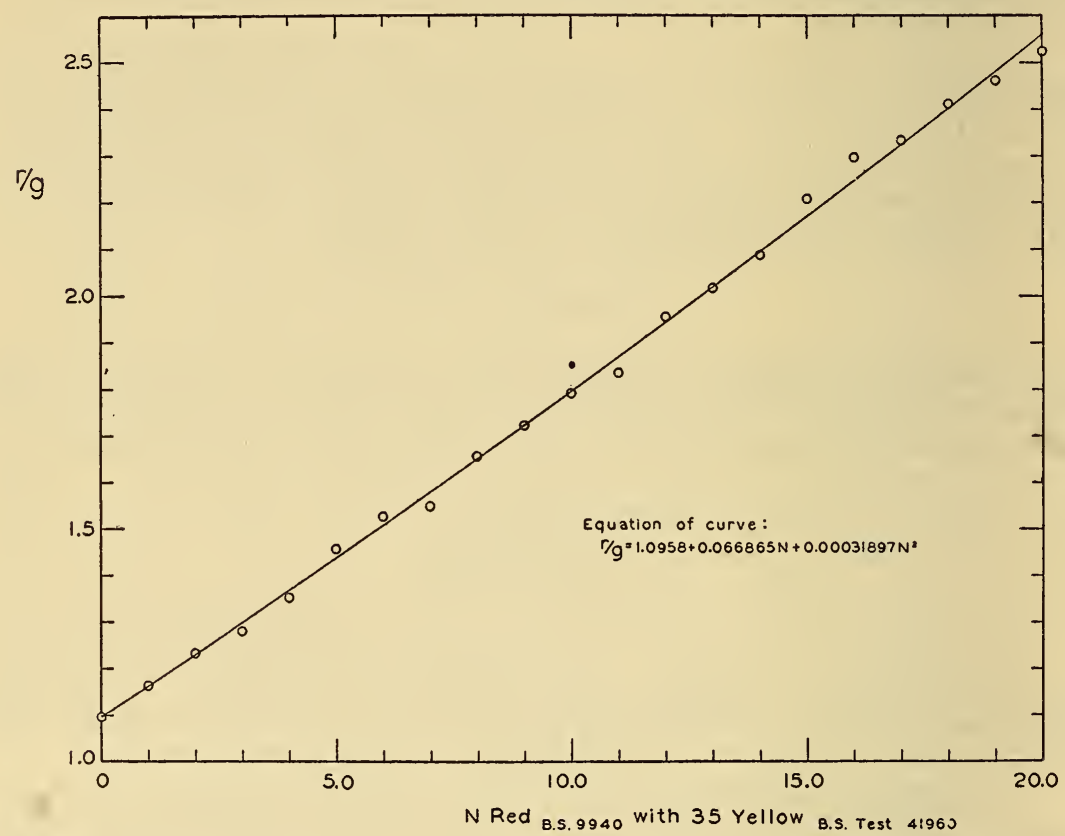

FIGURD 1.-Relation between $r / g$ and $N$ for Lovibond red glasses (with 35 yellow). $r / g$ is the ratio of red to green trilinear coordinates, $N$ the Lovibond numeral. Deviations of the circles from the curve illustrate the erratic variations in the scale as found for the Bureau glasses, BS 9940 .

To comply with requirement 4 of section I, it was necessary to test the $N^{\prime}$ numerals with respect to their additivity. For any scale to be \&dditive, it is necessary and sufficient that the unit be constant throughout the scale, so that any given glass should give a constant additional numerical value when combined with any of the various glasses comprising the scale. Such a test of the $N^{\prime}$ scale was carried out by computation as shown in table 1 .

${ }^{13}$ See, for example, BS Sci. Pap. S547, p. 8. In view of the relatively large variations existing among red glasses of the same nominal value, as found during the statistical investigation described in BS Research Pap. RP653, erratic deviations such as are shown in figure 1 are to be expected. 
TABLE 1.-Derivation of $N^{\prime \prime}$ unit and additive scale for Lovibond red glasses (BS 9940) combined with 35 yellow (BS test 41960)

[See text for explanation]

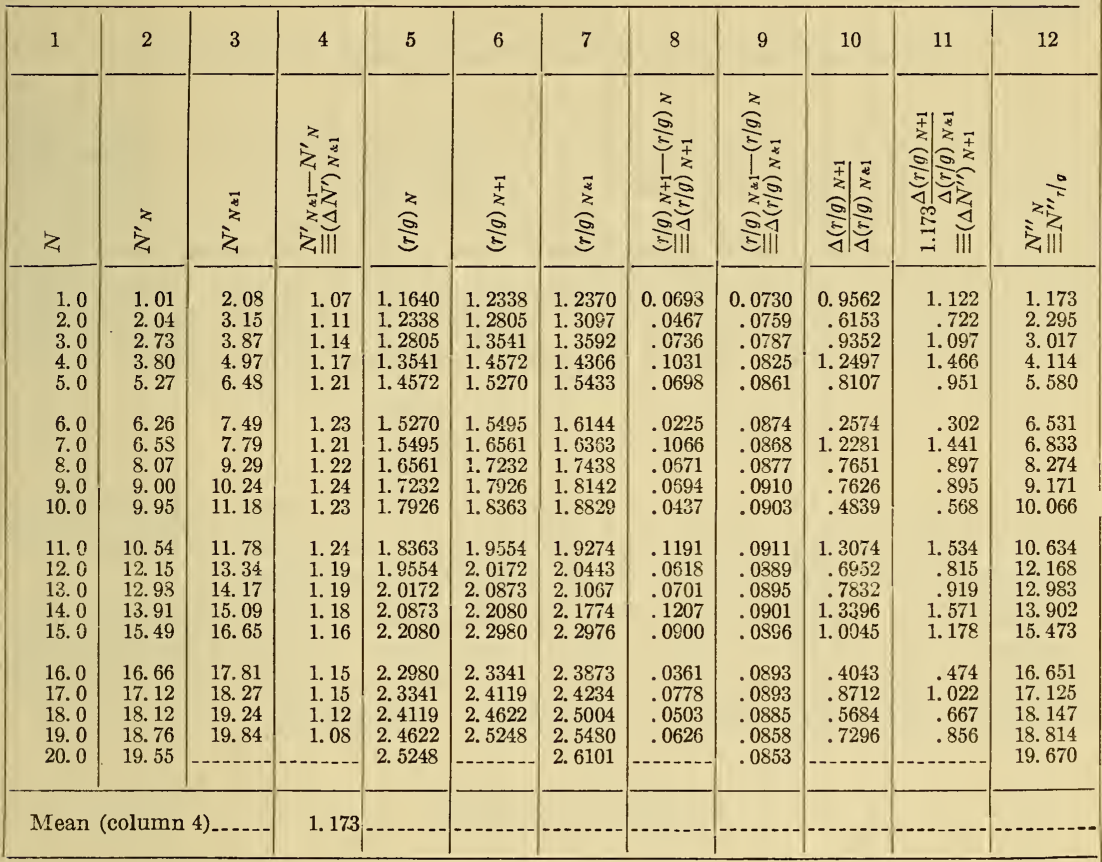

Values of $N^{\prime}{ }_{N}$ (column 2) are those obtained from the least-squares solution of the $(r / g, N)$ curve noted above. The $r / g$ values for the respective glasses are tabulated in column 5 , labelled $(r / g)_{N}$.

Columns 7 and 3 were derived as follows: The spectral transmissions of the respective glasses from 1 to 20 , in combination with the $35 \mathrm{Y}$ glass, were each in turn multiplied by the spectral transmission of the nominal unit glass $(N=1.0)$ and the $r, g$, and $b$ values for the respective combinations computed in the same manner as for the individual glasses. That is, the values of column 7 were derived from the respective spectral-transmission products, $35 \mathrm{Y} \times 1 \mathrm{R} \times 1 \mathrm{R}$, $35 \mathrm{Y} \times 2 \mathrm{R} \times 1 \mathrm{R}, 35 \mathrm{Y} \times 3 \mathrm{R} \times 1 \mathrm{R}$, etc., just as the values of column 5 had been derived from the similar products $35 \mathrm{Y} \times 1 \mathrm{R}, 35 \mathrm{Y} \times 2 \mathrm{R}$, $35 \mathrm{Y} \times 3 \mathrm{R}$, etc. The $N^{\prime}$ values of column 3 , designated as ${N^{\prime}}_{N \& 1}$, were derived from the $r / g$ values of column 7 by reading from the least-squares curve illustrated in figure 1.

The variable nature of the $N^{\prime}$ scale is shown by the values of $\Delta N^{\prime}{ }_{N \& 1}$ of column 4. It is seen that the nominal unit glass $(N=1.0)$, when combined with the other glasses, has an effective value varying from 1.07 to 1.24 , although the value obtained for the glass by itself (column 2) is only 1.01. The average value of this glass is approximately 1.17 instead of unity.

This variation of the unit throughout the scale, in addition to the erratic variations illustrated in figure 1 , shows clearly the need and importance of the regrading of Lovibond red glasses when they are 
to be used with $35 \mathrm{Y}$ or any other Lovibond yellow glass of high numeral. The adjustments required to establish a new $\left(N^{\prime \prime}\right)$ scale, insuring compliance with the additivity condition, will now be described.

\section{DERIVATION OF THE $N^{\prime \prime}$ UNIT AND NUMERALS}

It has just been shown that the $N^{\prime}$ scale is a smooth one but that since $\Delta N^{\prime}{ }_{N \& 1}$ is not constant, this scale does not satisfy the additivity condition. To make the new $\left(N^{\prime \prime}\right)$ scale satisfy this condition it must be such that $\Delta N^{\prime \prime}{ }_{N \& 1}$ is a constant; and since it is important to have numbers on the $N^{\prime \prime}$ scale nearly equal to numbers for the same glasses on the $N^{\prime}$ scale, this constant was taken at 1.173, the average value of $\Delta N^{\prime}{ }_{N \& 1}$ (see column 4). Assignment of $N^{\prime \prime}$ values to the glasses of the red series was then carried out according to the formula

$$
N^{\prime \prime}{ }_{N+1}=N^{\prime \prime}{ }_{N}+1.173 \frac{\Delta N^{\prime}{ }_{N+1}}{\Delta N^{\prime}{ }_{N \notin 1}}
$$

which defines the $N^{\prime \prime}$ value of any glass, $N+1$, in terms of the glass, $N$, just below it in the series. The further natural condition was added that $N^{\prime \prime}{ }_{N}=0$ for $35 \mathrm{Y}$ alone, or with clear glass.

Equation 1 is derived from the fact that the interval between any 2 glasses, $N$ and $N+1$, must bear a constant ratio to the interval represented by the nominal unit glass, $N=1$, regardless of the scale on which these intervals are expressed. Therefore,

$$
\frac{\Delta N^{\prime \prime}{ }_{N+1}}{\Delta N^{\prime \prime}{ }_{N \& 1}}=\frac{\Delta N^{\prime}{ }_{N+1}}{\Delta N^{\prime}{ }_{N \& 1}}
$$

The additivity of the $N^{\prime \prime}$ scale is automatically insured by giving $\Delta N^{\prime \prime}{ }_{N \& 1}$ a constant value, as stated above. If this value be taken at 1.173 and $\Delta N^{\prime \prime}{ }_{N+1}$ be expressed as $N^{\prime \prime}{ }_{N+1}-N^{\prime \prime}{ }_{N}$, equation 1 follows.

In the actual computation of the $N^{\prime \prime}$ values for the 20 red glasses the following nearly equivalent formula was used:

$$
N^{\prime \prime}{ }_{N+1}=N^{\prime \prime}{ }_{N}+1.173 \frac{\Delta(r / g)_{N+1}}{\Delta(r / g)_{N \& 1}}
$$

which substitutes $r / g$ steps for $N^{\prime}$ steps in formula 1 . The 2 formulas would be identical if $r / g$ were linearly connected to $N^{\prime}$; the relatively small coefficient of the $N^{2}$ term (see fig. 1 ) suggests that the 2 formulas are not significantly different, and tests by actual computation substantiate this.

The values of $N^{\prime \prime}{ }_{N}$ in column 12, table 1 , are obtained according to equation 2 , the values of the last term of this equation being given in column 11. Note, for example, that for $N=0$ equation 2 gives $1.173=0+1.173$; for $N=1,2.295=1.173+1.122$; and so on. These values of $N^{\prime \prime}{ }_{N}$ in view of their method of derivation will be hereafter referred to as $N^{\prime \prime}{ }_{r / g}$, as will be other values obtained specifically by way of spectral transmission and $r / g$ computation. However, the subscript $r / g$ will be omitted where the emphasis is primarily upon the $N^{\prime \prime}$ value rather than the mode of determination.

The values of $N^{\prime \prime}{ }_{r / g}$ thus obtained for the 20 glasses of set BS 9940 having values of $N=1.0,2.0,3.0, \ldots 20.0$ were used to plot a 
standard curve from which the value of $N^{\prime \prime}{ }_{r / g}$ for any other glass might be obtained after its spectral transmission had been determined. This curve is illustrated in the lower part of figure 2.
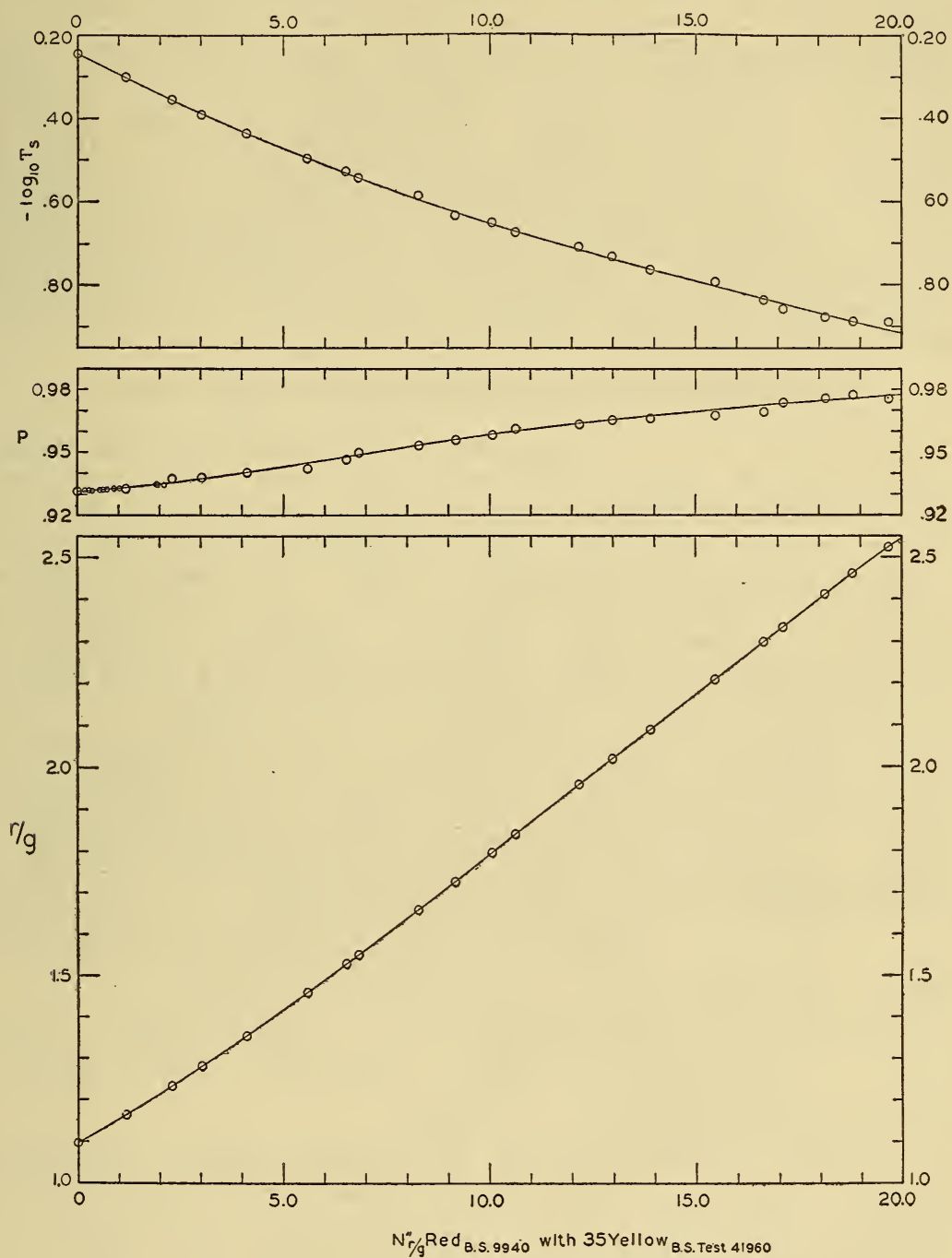

Frgure 2.-Standard curves on the $N^{\prime \prime}$ scale.

The lower curve compared with figure 1 shows the elimination of the erratic variations in the values assigned to the glasses of BS 9940 in the present standardization. The middle and upper curves show respectively the values of colorimetric purity, $P$, and sunlight transmission, $T_{8}$ (on a log scale), plotted as functions of $N " r / 0$.

Computation of $N^{\prime \prime}$ for glasses having values of $N$ equal to 1.0 or less. The curve just illustrated, $r / g$ vs $N^{\prime \prime}{ }_{r / g}$, was not, however, wholly suitable for obtaining values of $N^{\prime \prime}{ }_{r / g}$ for values of $N$ less than $1.0 .^{14}$

14 The spectral transmissions of the glasses, $N=0.01,0.02,0.03, \cdots \cdots 0.09,0.10,0.20,0.30 \cdots \cdots .90$, of BS 9940 , were measured in 1926-27, but have not been published. 
On the scale shown, values could not be read with the desired precision, and any attempt at magnification would have been rather unsatisfactory because of the slight curvature of the line in this region. A straight line was, therefore, assumed to hold between the points representing $N^{\prime \prime}{ }_{r / g}=0$ and 1.173 , the equation of which is ${ }^{15} N^{\prime \prime}{ }_{r / g}=$ $17.22215(r / g-1.09587)$. Values of $N^{\prime \prime}{ }_{r / g}$ derived from this equation did not differ from those read from the graph by more than 0.01 . This agreement justifies the use of the equation, since an uncertainty of 0.01 is negligible so far as the absolute values are concerned. For these fractional glasses, however, it was desired to determine values with a computational uncertainty not greater than 0.001 so that differences between glasses nearly alike could be obtained with greater precision. The equation has, therefore, been used for all computations of $N^{\prime \prime}{ }_{r / g}$ for values of $N=1.0$ or less. It should not be used for values of $N$ much greater than 1.0.

\section{STANDARD PURITY AND TRANSMISSION CURVES}

The value of $N^{\prime \prime}{ }_{r / 0}$ to be assigned a Lovibond red glass in combination with 35 yellow is valid only under certain additional conditions. Not merely the hue but also the saturation and brilliance must be of given value if one color is to match another satisfactorily. For the Lovibond red glasses with 35 yellow, it is necessary, therefore, to consider standard colorimetric-purity and light-transmission curves and corresponding tolerances. Otherwise, "grades" via $r / g$ could be assigned a large variety of glasses giving colors differing enormously from those of Lovibond red with 35 yellow.

Accordingly, values of colorimetric purity, ${ }^{16} P$, were computed from the trilinear coordinates $(r, g, b)$, by the routine method. ${ }^{17}$ The values obtained are shown in figure 2 , middle section, together with the curve adopted as standard for Lovibond red glasses with 35 yellow. It may be noted that values were plotted for some of the fractional glasses and for a few extra glasses near $N^{\prime \prime}{ }_{r / g}=2$, in addition to the values for the glasses used in deriving the $\left(r / g, N^{\prime \prime}{ }_{r / g}\right)$ curve. This made possible a more accurate estimate of the true course of the purity curve for the lower-valued glasses.

The standard light-transmission curve was determined in a similar manner. Transmissions for Abbot-Priest sunlight, $T_{s}$, were computed by a previously described method. ${ }^{18}$ Values of $-\log _{10} T_{s}$ thus obtained are plotted in fig. 2 , top section. ${ }^{19}$

In general, of course, the values of purity and sunlight transmission computed for any Lovibond red glass will not fall exactly on the standard curves, any more than do the values for the glasses of BS 9940. The question of permissible tolerances has, therefore, to be considered. The purity deviations and tolerances may be expressed as $P-P_{N^{\prime \prime}}$, where $P$ is the actual purity of the glass as defined above and $P_{N^{\prime \prime}}$ is the purity as read from the standard curve at the value of $N^{\prime \prime}{ }_{r / g}$ found for the glass. In figure 2 this difference

\footnotetext{
${ }^{15}$ A slight inconsistency may be noted between the value of $r / g$ here given for $35 \mathrm{Y}(=1.09587)$ and that given previously $(a=1.0958)$, which is due to rejection errors. The use of 1.0958 in the present equation
would not change any of the values of $N^{\prime \prime} r / 0$ by more than 0.001 .

${ }_{16}$ Irwin G. Priest, The computation of colorimetric purity, J.O.S.A. \& R.S.I., 9, 503(1924).

17 Deane B. Judd, The computation of colorimetric purity, J.O.S.A. \& R.S.I., 13, 143(1926).

18 BS Sci. Pap. S547, p. 17.

19 The value for $N^{\prime \prime}{ }_{* / 0}=0$ was determined as follows: $T$, for $35 Y_{B S}$ tent 41,900 (alone) equals 0.6319 . The value of $T_{8}$ for a zero glass was taken as 0.901 , which is the mean of the values given for $T_{s}$ for the zero red, yellow, and blue glasses (BS Sci. Pap. S547, tables 1, 2, and 3). $0.6319 \times 0.901=0.5693$; and $-\log _{10}$ $0.5693=0.2447$, which is the value of the intercept as plotted.
} 
is represented by the vertical distances between the plotted points and the standard purity curve. The magnitude of these deviations is further illustrated and discussed in section IV, where the question of tolerances is considered.

Deviations of the actual sunlight transmissions (or $-\log _{10} T_{s}$ values) from the values proper to $N^{\prime \prime}{ }_{T / g}$ could be similarly expressed, and are likewise illustrated in figure 2 by the vertical distances between the plotted values and the standard $-\log _{10} T_{s}$ curve. As explained in footnote 6, p. 434, however, the additivity condition refers to chromaticity alone, and in the determination of $N^{\prime \prime}$ the sunlight transmission is eliminated as a determining factor. Such data would be of no use under the present customary conditions of using the glasses to grade oils. It is, of course, true that there must be limits of such transmission, even though wide, outside of which a glass would be unusable in the oil trade. The value of such limits is not known, however, and since no glass has been found objectionable in this respect, the question of luminous transmissions of the glasses will not be further considered in the present paper.

\section{SELECTION OF STANDARDS FOR ROUTINE CALIBRATION OF LOVIBOND RED GLASSES}

The purpose of the Bureau's standardization was not merely the establishment of an accurate additive scale but also the selection of a certain number of glasses so distributed in $N^{\prime \prime}$ value that glasses submitted for test could be directly compared with them and graded. While the calibration of any Lovibond red glass with 35 yellow can be carried out via spectral transmission measurement and computation, as illustrated in the previous section, this would be a much too laborious and costly procedure for calibrating the thousands of Lovibond red glasses used in the vegetable oil industry. With standardized glasses available, the time required for the calibration of a glass by the direct-comparison method is but a small fraction of that necessary by the spectrophotometric method.

The obvious choice of glasses to serve as comparison standards would be those whose values of $N^{\prime \prime}$ equal, respectively, $0.10,0.20$, $\ldots \ldots 0.90,1.0,2.0, \ldots \ldots 10.0,20.0$; that is, a decimal system, so that any test glass could be matched by a combination of not more than 2 (or 3 , above 10.0) glasses. ${ }^{20}$ Accordingly, most of the red glasses of BS 9940 which had not already been standardized ${ }^{21}$ were compared with combinations of the standardized glasses giving as nearly as possible the desired values of exact tenths and units on the $N^{\prime \prime}$ scale. ${ }^{22}$ Four observers ${ }^{23}$ took part in this study, the observations being made with a Martens photometer having a 35Y glass over the ocular and with illumination produced by natural north skylight through milk glass. ${ }^{24}$ Those glasses nearest matching the selected

\footnotetext{
20 Since the Lovibond red glass of smallest nominal value $(N=0.01)$ has an $N^{\prime \prime}$ value of approximately 0.1 , it is not feasible to extend the decimal system to glasses having values of $N^{\prime \prime}$ less than 0.1 . Furthermore, the change in chromaticity caused by a glass of $N^{\prime \prime}=0.1$ (when combined with 35 yellow, $N$ red) is so small that further subdivision would be an unnecessary refinement, even if possible.

${ }_{21}$ 'That is, ali the glasses excepting those having values of $N=0.01,0.02, \cdots \cdots 0.09,0.10,0.20, \cdots 0.90$, $1.0,2.0, \cdots \cdots 10.0$. This comparison did not include glasses with values of $N$ greater than 10.0.

22 It was possibie by combining not more than 3 of the standardized glasses to secure combinations having values of $N^{\prime \prime}$ dilfering from the desired exact tenths and units by not more than \pm 0.006 over the range from $N^{\prime \prime}=0.1$ to $N^{\prime \prime}=10.0$.

${ }_{23}$ Deane B. Judd, J. O. Riley, and the authors made these observations under the supervision and direc. tion of Mir. Priest.

${ }_{24}$ This apparatus is illustrated in Oil and Fat Industries, 5, 17 (January 1928).
} 
combinations were then measured spectrophotometrically and the values of $N^{\prime \prime}{ }_{r / g}$ computed. ${ }^{25}$ Other glasses from BS 9940 were later measured until to date a total of 78 red glasses from BS 9940 have undergone spectrophotometric standardization. Those selected as working standards for the regrading of glasses submitted for calibration are listed in BS Research Pap. RP653, p.271.

\section{EXPERIMENTAL TESTS OF ADDITIVITY OF THE $N^{\prime \prime}$ SCALE}

The values of $N^{\prime}$ and $N^{\prime \prime}$, and therefore the scale and unit, established with the glasses of BS 9940 in the present standardization would be essentially unchanged regardless of (1) the particular $35 \mathrm{Y}$ glass used in combination with the red glasses, (2) the energy distribution used to represent the source, within certain limits, and (3) the visual characteristics assumed for the hypothetical normal observer - although once the scale is established, the exact values of the various constants used in its derivation must always be used in computing $N^{\prime \prime}{ }_{r / g}$ for any unknown glass. Reasonable variations of these factors do not, therefore, have any bearing on the relative merits of the $N^{\prime \prime}$ and $N$ scales. It should be remembered, however, that all the conclusions stated refer to Lovibond red glasses in combination with 35 yellow. Similar conclusions might perhaps be reached by a study of the red glasses alone (without $35 \mathrm{Y}$ ) or in combination with other glasses, but such is not demonstrated in the present paper.

The computational superiority of the $N^{\prime \prime}$ scale over the $N$ and $N^{\prime}$ scales has already been demonstrated. There remains, however, the very important question of the practical utility of the $N^{\prime \prime}$ scale. This has been satisfactorily answered by means of various tests showing its additive nature. These tests have been gradually accumulated since the scale was inaugurated. A brief résumé of the results of several of these follows.

1. The practicability of the $N^{\prime \prime}$ scale was to a considerable degree ascertained at the time the standards were selected. It was found that (1) a given chromaticity could be matched by combinations of glasses having nearly the same value of $N^{\prime \prime}{ }_{r / g}$ but considerably differing values of $N,(2)$ the $N^{\prime \prime}$ values of the single glasses selected to match the combinations were on the average not significantly different ( 0.04 less) from the $N^{\prime \prime}$ values of the combinations.

2. An extensive intercomparison of the standards from 0.1 to 10.0 was later made by D. B. Judd and G. K. Walker with improved illumination. ${ }^{26}$ In this investigation, various standards were combined in pairs and a third standard selected which nearly matched the combination. The residual difference was then estimated; or, if such difference was greater than $N^{\prime \prime}=0.1$, a fourth standard approximating the difference was introduced and the residual difference again estimated. The $N^{\prime \prime}$ value of the combination of the first 2 glasses was then compared with the $N^{\prime \prime}$ value of the third glass plus residual (or plus fourth glass plus residual). The latter exceeded the former on the average by approximately 0.03 , this difference being, however, opposite in sign to the average difference found under 1 , just above. Individual

\footnotetext{
${ }_{25}$ The degree of agreement between values of $N^{\prime \prime}$ obtained via spectral transmission measurement and computation and values of $N^{\prime \prime}$ obtained by direct comparison with standardized glasses, is iilustrated in sections IV and V.

${ }_{26}^{26}$ Artificial sunlight, apparatus as described in BS Research Paper RP653.
} 
discrepancies rarely exceeded 0.12 ; the agreement was considered sufficiently satisfactory that a contemplated $N^{\prime \prime \prime}$ scale was not formulated.

3. A series of red glasses, $N=0.1,0.2 \ldots 0.9,1.0,2.0, \ldots 10.0$, were submitted under BS test $41,960 .{ }^{27}$ In the course of this test, it seemed desirable to see if the same values of $N^{\prime \prime}$ would be obtained for the fractional glasses when they were combined with 7.0R as when used alone (in both cases in combination with $35 \mathrm{Y}$, as usual). Accordingly, the spectral transmission of each fractional glass was combined with that of 7.0R, 35Y and values of $N^{\prime \prime}{ }_{\tau / g}$ computed for the combinations. The values of $N^{\prime \prime}{ }_{r / 0}$ for $7.0 \mathrm{R}, 35 \mathrm{Y}$ alone was then subtracted from the values for the combinations and the resulting differences compared respectively with the values of $N^{\prime \prime}{ }_{r / 8}$ obtained for the fractional glasses alone (with $35 \mathrm{Y}$ ) obtained in the regular way. The differences in no case exceeded 0.02 , indicating that within this tolerance these fractional glasses had the same respective values at these 2 widely differing places on the scale.

4. Most conclusive of all is the evidence afforded by the observations made on the approximately 2,300 red glasses that have been submitted for calibration. In these measurements, ${ }^{28}$ the test glass is given a tentative regrade $\left(N^{\prime \prime}\right)$ value by comparison with the standard glasses of BS 9940. After all the glasses submitted at any one time have been thus tentatively graded, they are intercompared. That is, a standard is chosen equal (or closely equivalent) in $N^{\prime \prime}$ value to the difference between the tentative values assigned to adjacent test glasses. This is done throughout the whole range of test glasses. If a satisfactory intercheck is not observed, the test glasses involved are reexamined, the cause of the discrepancy located, and new values assigned where necessary, until finally, the whole set of test glasses is consistent within itself and with the standards. This intercheck would prove impossible if the standards themselves were not additive within the desired tolerances. The fact that it has been possible for the many hundreds of test glasses submitted insures the additivity of the standards within the desired tolerances.

\section{COMPARISON OF $N^{\prime \prime}$ VALUES OBTAINED VIA SPEC- TRAL TRANSMISSION AND COMPUTATION OF $r / g$, AND VIA DIRECT COMPARISON WITH THE STANDARDS}

It has been shown in the previous section that the scale established for Lovibond red glasses (with $35 \mathrm{Y}$ ) at the Bureau is an additive one within the tolerances considered satisfactory for calibrating glasses to be used in the grading of vegetable oils. The 2,300 Lovibond red glasses already submitted for calibration have been graded in terms of this additive scale, the values reported being stated (in each report) to have a maximum uncertainty of 0.1 for $N$ less than or equal to 10.0 , of 0.2 for $N$ greater than 10.0 but equal to or less than 16.0 , and of 0.4 for $N$ greater than 16.0 .

It is desirable, not only that the scale be additive as already defined and illustrated, but also that the same value of $N^{\prime \prime}$ be obtained, whether by way of spectral transmission measurements and computation of $r / g\left(N^{\prime \prime}{ }_{r / g}\right)$ or by direct comparison with the Bureau's standard glasses $\left(N^{\prime \prime}{ }_{\text {obs }}\right)$.

${ }^{27}$ The spectral transmissions of these glasses are published in BS Sci. Pap. S547\%

${ }_{28}$ See BS Research Pap. RP653. 
The first test of this kind was made upon the red glasses of BS test 41,960 , previously noted. The discrepancies between $N^{\prime \prime}{ }_{\text {obs }}$ and $N^{\prime \prime}{ }_{r / 0}$, in only one case exceeding $0.06(0.10$ for $N=10.0$ ), were not considered unduly large, since part of the discrepancy would doubtless be caused by errors in the spectral transmission. ${ }^{29}$

Similar comparisons of $N^{\prime \prime}{ }_{r / g}$ and $N^{\prime \prime}{ }_{\text {obs }}$ were later made on 2 other groups of glasses, submitted under BS tests 59,139 and 432-1. ${ }^{30}$ The results are shown in table 2.

TABLE 2.-Comparison of values of $N^{\prime \prime}{ }_{\text {obs }}$ with values of $N^{\prime \prime}{ }_{r / o}$ obtained from original $\left(r / g, N^{\prime \prime}{ }_{r / g}\right)$ standard curve

[The discrepancies shown in column 5 led to the revision of the standard curve for values of $N$ greater than 5.0 , as explained in sec. V; these discrepancies were largely eliminated by this revision. There is but little correlation between values of $N^{\prime \prime}{ }_{\text {obs }}-N^{\prime \prime}{ }_{r / o}$ and values of $\left.P-P_{N \prime \prime}\right]$

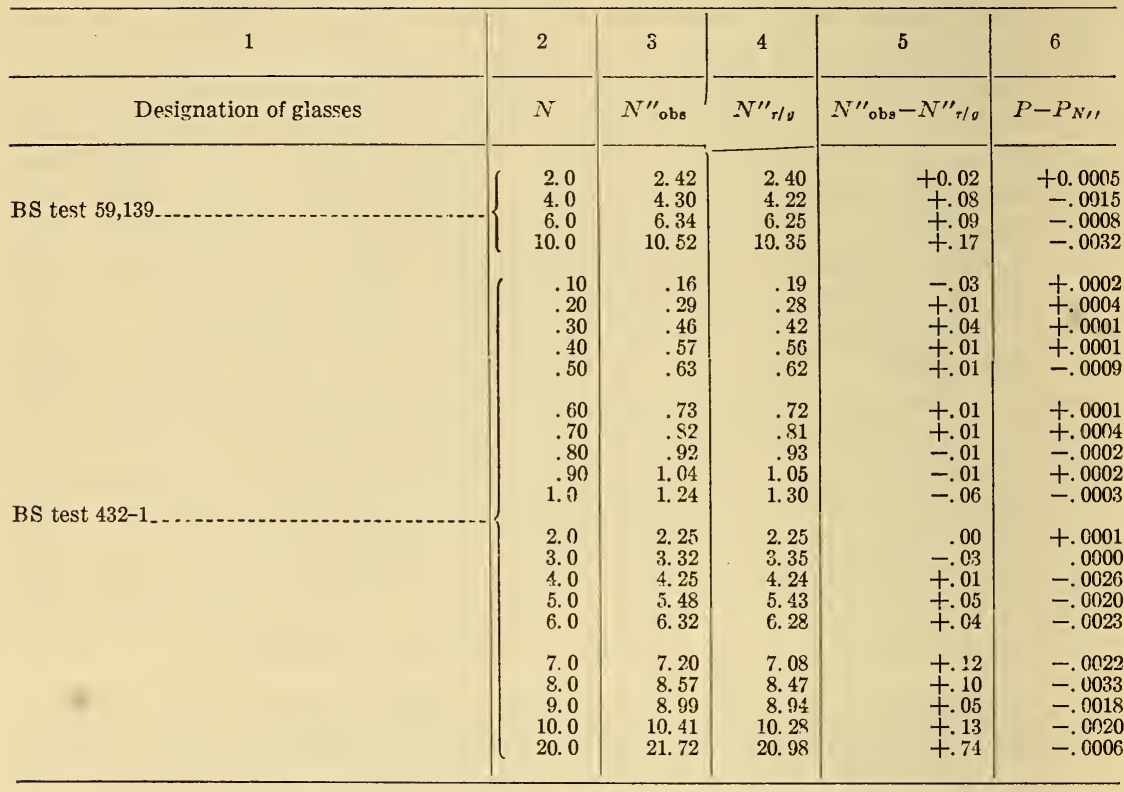

An examination of these data (including also those of test 41,960 which are not shown) indicated that no important discrepancy existed between the values of $N^{\prime \prime}{ }_{\text {obs }}$ and $N^{\prime \prime}{ }_{r / g}$ for values of $N=0.1$ to $N=3.0$. From $N=4.0$ to $N=10.0$ (and 20.0), however, there was shown an increasing tendency for the values of $N^{\prime \prime}{ }_{\text {obs }}-N^{\prime \prime}{ }_{r / g}$ to be positive, this discrepancy in some cases exceeding the maximum uncertainty of 0.1 (or of 0.4 for $N=20.0$ ) given in the reports made on glasses submitted for calibration.

From table 2 it might be suspected that the differences, $N^{\prime \prime}{ }_{\text {obs }}-$ $N^{\prime \prime}{ }_{r / g}$, were related to some extent to the purity deviations, $P-P_{N^{\prime \prime}}$, since a tendency may be noted for the largest positive values of the former to group with the largest negative values of the latter. However, computation (including data on the glasses of test 41,960 ) shows

\footnotetext{
${ }_{29}$ The magnitude of the differences in $N^{\prime \prime}{ }_{r / 0}$ to be expected from errors in spectral transnaission is illustrated in the appendix, p. 449. 30 Acknowledgment is made to D. B. Judd and Mabel E. Brown for assistance in securing the data of
this test.
} 
this correlation to be only 20 percent, approximately, with a probable error half as large. Since the discrepancies between $N^{\prime \prime}{ }_{\text {obs }}$ and $N^{\prime \prime}{ }_{r / g}$ can be adequately explained otherwise (see next section), it may be concluded that there is no important relation between these discrepancies and the purity deviations.

The question of purity tolerances may, however, be considered in this connection. Four glasses have been found with values of $P-P_{N^{\prime \prime}}$ greater than -0.0050 , the maximum being -0.0066 . In none of these cases did the values of $N^{\prime \prime}{ }_{\text {obs }}-N^{\prime \prime}{ }_{r / g}$ exceed +0.05 . This further illustrates the lack of correlation between these quantities and shows that the question of purity tolerances has proved of little importance in connecton with the 2,300 glasses already graded.

No specific tolerances have, therefore, been fixed for the values of $P-P_{N^{\prime \prime}}$. However, it seems undesirable that this quantity exceed 0.005 . Such a value is two or three times the least difference perceptible with our conditions of observation and makes the determination of $N^{\prime \prime}{ }_{\text {obs }}$ relatively difficult. None of the 78 calibrated glasses of BS 9940 has a value of $P-P_{N^{\prime \prime}}$ greater than 0.0036 , and the values for the standards selected for use in the grading of glasses submitted for calibration do not exceed 0.0012 .

\section{REVISION OF THE $\left(r / g, N^{\prime \prime}\right)$ STANDARD CURVE}

Since the values of table 2 were based on extensive and repeated measurements, it seemed necessary to reexamine the standards of higher value used in the determination of $N^{\prime \prime}{ }_{\text {obs }}$. Such redetermination did not have as a purpose the assignment of new values of $N^{\prime \prime}{ }_{T / 0}$ to the standards. This was unnecessary because the scale had been shown in various ways to be additive to the desired degree (see sec. III), and was highly undesirable because of the large number of glasses that had already been graded in terms of these standards. The purpose was (1) a remeasurement of the spectral transmissions ${ }^{31}$ of the higher-valued working standards, (2) a recomputation of $\mathrm{r} / \mathrm{g}$ to see if the larger discrepancies would be reduced, (3) if so, an empirical revision of the $\left(r / g, N^{\prime \prime}\right)$ curve of such kind if possible that the same values of $N^{\prime \prime}{ }_{r / g}$ would be obtainable with the new values of $r / g$. Such revision would be based also on the values of $N^{\prime \prime}{ }_{\text {obs }}$ (table 2) for which accurate values of $r / g$ were also available. This would further insure the continued additivity of the scale and for values of $N$ greater than 10.0 put it on a more certain basis than before. ${ }^{32}$

In table 3 is summarized all the data entering into the reexamination and revision of the $\left(r / g, N^{\prime \prime}\right)$ curve. The values are plotted in figure 3. It was highly desirable, as stated above, that the values of $N^{\prime \prime}{ }_{r / g}$ originally assigned the standard glasses remain unchanged. Hence the new values of $r / g$ are plotted against the original values of $N^{\prime \prime}{ }_{r / g}$. In the case of the standards, $N=12.0,13.0,17.0$, and 20.0, the values of $r / g$ are also plotted against the values of $N^{\prime \prime}$ obs obtained for these 4 glasses by the regular method of comparison and grading in terms of standards having values of $\mathrm{N}^{\prime \prime}$ equal to 10.0 or less.

\footnotetext{
31 Iniproved apparatus and technique gave expectation that more accurate values would be obtained. (See Appendix.)

32 It was originally intended not to accept glasses for calibration having values of $N$ greater than 10.0 While the original standardization of the glasses of BS 9940 included all the exact integer glasses from 10.0 to 20.0 , there had never been any extensive experimental tests of the additivity of the scale in this region.
} 
TABLE 3.-Data on which is based the revision of the $\left(r / g, N^{\prime \prime}{ }_{r / o}\right)$ standard curve

\begin{tabular}{|c|c|c|c|c|c|c|}
\hline 1 & 2 & 3 & 4 & 5 & 6 & 7 \\
\hline \multirow{2}{*}{ Designation of glasses } & \multirow{2}{*}{$N$} & \multirow{2}{*}{$\begin{array}{c}N^{\prime \prime}{ }_{r / o} \\
\text { (original cal- } \\
\text { ibration) }\end{array}$} & \multirow{2}{*}{$\begin{array}{c}r / g \\
(1930-31)\end{array}$} & \multirow{2}{*}{$N^{\prime \prime}$ obs } & \multicolumn{2}{|c|}{$\begin{array}{l}\text { Deviation from cor- } \\
\text { rected curve for }\end{array}$} \\
\hline & & & & & $N^{\prime \prime} r / \sigma$ & $N^{\prime \prime}$ obs \\
\hline \multirow{6}{*}{ Standards of BS $9940 \ldots$} & $\begin{array}{l}0.86 \\
1.8 \\
2.8 \\
3.9 \\
4.9\end{array}$ & \begin{tabular}{l|}
1.003 \\
1.95 \\
2.99 \\
3.94 \\
5.08
\end{tabular} & $\begin{array}{l}1.1558 \\
1.2149 \\
1.2766 \\
1.3419 \\
1.4205\end{array}$ & - & $\begin{array}{r}-0.02 \\
-.03 \\
+.03 \\
-.01 \\
.00\end{array}$ & 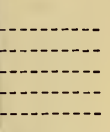 \\
\hline & \begin{tabular}{l|}
5.4 \\
5.6 \\
6.0 \\
6.8 \\
7.6
\end{tabular} & \begin{tabular}{l|}
5.82 \\
6.16 \\
6.531 \\
6.85 \\
7.59
\end{tabular} & $\begin{array}{l}1.4721 \\
1.4994 \\
1.5224 \\
1.5466 \\
1.5982\end{array}$ & & $\begin{array}{r}.00 \\
-.04 \\
.00 \\
-.01 \\
+.03\end{array}$ & - \\
\hline & \begin{tabular}{r|}
8.2 \\
9.0 \\
9.8 \\
12.0 \\
13.0
\end{tabular} & $\begin{array}{c}8.04 \\
9.171 \\
10.00 \\
12.168 \\
12.983\end{array}$ & $\begin{array}{l}1.6376 \\
1.7174 \\
1.7830 \\
1.9434 \\
2.0023\end{array}$ & $\begin{array}{l}12.19 \\
12.92\end{array}$ & $\begin{array}{r}-.06 \\
.00 \\
-.04 \\
.00 \\
+.02\end{array}$ & $\begin{array}{r}+0.02 \\
-.04\end{array}$ \\
\hline & $\begin{array}{l}17.0 \\
20.0\end{array}$ & $\begin{array}{l}17.125 \\
19.670\end{array}$ & $\begin{array}{l}2.3094 \\
2.4994\end{array}$ & $\begin{array}{l}17.22 \\
20.05\end{array}$ & $\begin{array}{l}-.03 \\
-.22\end{array}$ & $\begin{array}{l}+.06 \\
+.16\end{array}$ \\
\hline & $\begin{array}{l}.10 \\
.20 \\
.30 \\
.40 \\
.50\end{array}$ & & $\begin{array}{l}1.1069 \\
1.1122 \\
1.1203 \\
1.1286 \\
1.1321\end{array}$ & $\begin{array}{l}.16 \\
.29 \\
.46 \\
.57 \\
.63\end{array}$ & - n & $\begin{array}{l}-.02 \\
+.01 \\
+.04 \\
+.01 \\
+.01\end{array}$ \\
\hline & $\begin{array}{r}.60 \\
.70 \\
.80 \\
1.0 \\
.0\end{array}$ & & $\begin{array}{l}\text { 1. } 1376 \\
\text { 1. } 1427 \\
\text { 1. } 1498 \\
1.1570 \\
1.1717\end{array}$ & $\begin{array}{r}.73 \\
.82 \\
.92 \\
1.04 \\
1.24\end{array}$ & $-\cdots-$ & $\begin{array}{r}+.01 \\
+.01 \\
.00 \\
.00 \\
-.04\end{array}$ \\
\hline Do & $\begin{array}{l}2.0 \\
3.0 \\
4.0 \\
5.0 \\
6.0\end{array}$ & & $\begin{array}{l}\text { 1. } 2311 \\
\text { 1. } 3022 \\
\text { 1. } 3618 \\
1.4464 \\
1.5084\end{array}$ & $\begin{array}{l}2.25 \\
3.32 \\
4.25 \\
5.48 \\
6.32\end{array}$ & & $\begin{array}{r}.00 \\
-.02 \\
+.01 \\
+.03 \\
-.01\end{array}$ \\
\hline t. & $\begin{array}{r}7.0 \\
8.0 \\
9.0 \\
10.0 \\
20.0\end{array}$ & & $\begin{array}{l}1.5676 \\
1.6704 \\
1.7053 \\
1.8088 \\
2.6208\end{array}$ & $\begin{array}{r}7.20 \\
8.57 \\
8.99 \\
10.41 \\
21.72\end{array}$ & & $\begin{array}{r}+.05 \\
+.03 \\
+.03 \\
+.03 \\
.00\end{array}$ \\
\hline BS test $59,139 \ldots$ & $\begin{array}{r}2.0 \\
4.0 \\
6.0 \\
10.0\end{array}$ & & $\begin{array}{l}\text { 1. } 2405 \\
\text { 1. } 3611 \\
1.5061 \\
1.8141\end{array}$ & $\begin{array}{r}2.42 \\
4.30 \\
6.34 \\
10.52\end{array}$ & $\cdots$ & $\begin{array}{l}+.02 \\
+.07 \\
+.04 \\
+.07\end{array}$ \\
\hline BS test $62,704-\mathrm{L}_{\text {- }}$ & 20.0 & & 2. 6091 & 21.55 & $\cdots$ & .00 \\
\hline $\begin{array}{l}\text { Alg. mean }(N=1.0 \text { to } N=20.0, \text { ex } \\
\text { cluding } N=20.0, \text { BS } 9940)\end{array}$ & & & & & -.00 & +.018 \\
\hline
\end{tabular}

For the respective test glasses the values of $r / g$ are plotted against the values of $N^{\prime \prime}{ }_{\text {obs. }}$. Provided the values for the test glasses are found to plot consistently with those for the standards, the resulting curve will satisfy the various requirements that have been noted, viz:

1. It will be on the average in accord with the values of $N^{\prime \prime}{ }_{r / g}$ originally assigned to the standards of BS 9940.

2 . It will be additive, inasmuch as it will be consistent with values of $N^{\prime \prime}$ obs over the whole range.

3 . Values of $N^{\prime \prime}$ obtained via spectral transmission and computation will closely check those obtained by direct observation. 
In figure 3 the dotted curve represents the original $\left(r / g, N^{\prime \prime}\right)$ curve shown in figure 2. The continuous line is the empirically corrected curve, drawn to fit the plotted points as accurately as possible. However, no correction was considered necessary for values of $N^{\prime \prime}$ less than 5.0, and the 2 curves deviate perceptibly only above this value.

In table 3, columns 6 and 7 , are shown the deviations of the plotted values from the corrected curve. The following points may be noted:

1. None of the values of $N^{\prime \prime}{ }_{r / g}$ assigned to the standards, nor of $N^{\prime \prime}{ }_{\text {obs }}$ obtained by comparison with the standards, deviate from the corrected curve by more than \pm 0.07 , excepting only $N=20.0$, BS 9940.

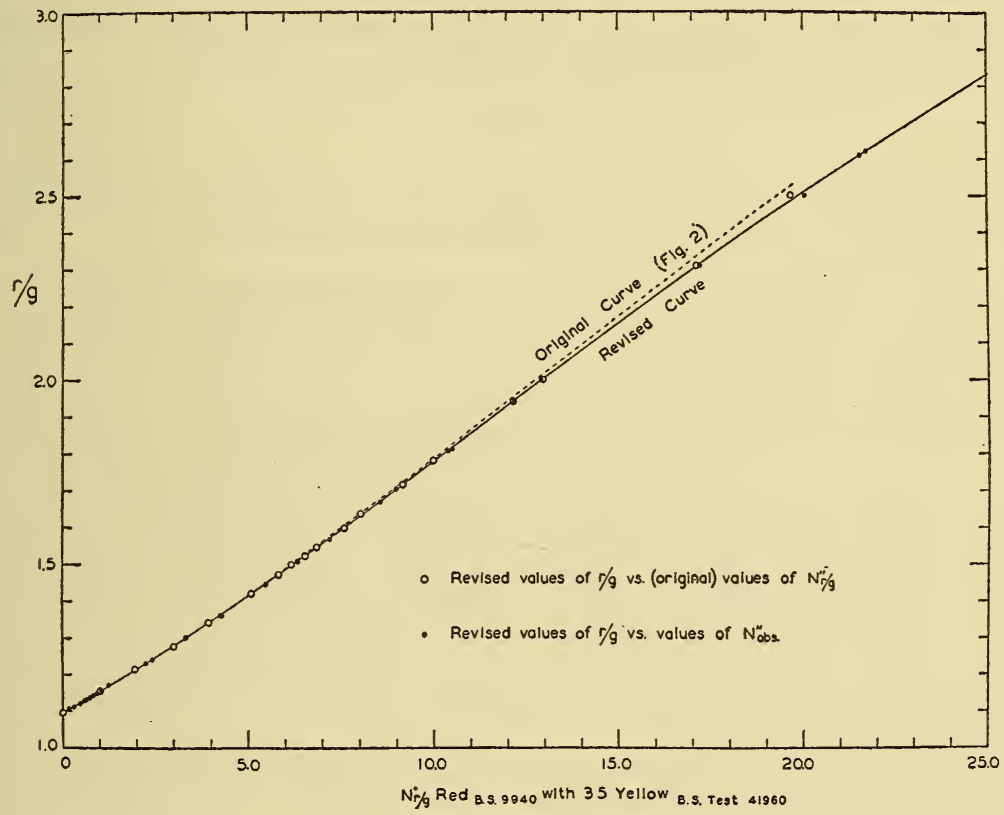

FIGURE 3.-Revision of standard $\left(r / g, N^{\prime \prime}{ }_{r / 0}\right)$ curve.

Data taken from table 3.

2. The deviations, without any exception, fall within tolerances adopted as satisfactory for grading Lovibond red glasses with 35 yellow. These tolerances have been stated at the beginning of section IV.

3. As shown by the algebraic means of the deviations (columns 6 and 7 ), the average discrepancy between the values of $N^{\prime \prime}{ }_{r / g}$ and $N^{\prime \prime}{ }_{\text {obs }}$ is less than 0.03 . $\quad\left(-0.00_{9}-0.01_{5}=-0.02_{4}\right.$.)

4. By use of this corrected curve, essentially the same values of $N^{\prime \prime}$ may be obtained from accurate spectrophotometric measurements as are obtained by direct comparison with the standards of BS 9940 .

5 . The values in column 7 of table 3 compared with the values for the same glasses given in the fourth column of table 2 show the improvement effected at the higher values by the corrected curve. 


\section{REPRESENTATIVE NATURE OF THE $N^{\prime \prime}$ UNIT AND SCALE}

It has already been shown ${ }^{33}$ that on the basis of the first 1,000 glasses graded, the relation between the $N$ and $N^{\prime \prime}$ scales may on the average be expressed by the least-squares equation

$$
N^{\prime \prime}=1.02 N+0.14
$$

If the equation be derived on the basis of only those glasses which have values of $N=1.0,2.0,3.0, \ldots \ldots 20.0$, the following is obtained:

$$
N^{\prime \prime}=1.014 N+0.21
$$

This may be compared with the similar equation obtained with the 20 glasses of BS $9940(N=1.0,2.0,3.0, \ldots .20 .0)$ :

$$
N^{\prime \prime}=0.987 N+0.26
$$

A comparison of equations 4 and 5 shows a significant difference in the average $N^{\prime \prime}$ values for the 2 cases, as illustrated in table 4 . These

TABLE 4.-Comparison of values of $N^{\prime \prime}$ computed from equations 4 and 5

\begin{tabular}{|c|r|r|r|}
\hline \multirow{2}{*}{$N$} & \multicolumn{3}{|c|}{$N^{\prime \prime}$} \\
\cline { 2 - 4 } & Equation 4 & Equation 5 & 4 minus 5 \\
\hline & & & \\
\cline { 3 - 4 } 0.0 & 0.21 & 0.26 & -0.05 \\
1.0 & 1.22 & 1.25 & -.03 \\
1.85 & 2.09 & 2.09 & .00 \\
5.0 & 5.28 & 5.20 & +.08 \\
10.0 & 10.35 & 10.13 & +.22 \\
20.0 & 20.49 & 20.00 & +.49 \\
\hline
\end{tabular}

values show the important differences that exist for values of $N$ greater than 5.0 .

Of still more importance, however, is a comparison of the values of $\Delta N^{\prime \prime} / \Delta N$ as derived from equations 4 and 5 . These values, that is, the slopes of the lines represented by the equations, are respectively 1.014 and 0.987 , and the ratio of the first to the second is 1.027 . In other words, the average $N^{\prime \prime}$ difference between the adjacant glasses in the series $N=1.0,2.0,3.0, \cdots 20.0$ is 2.7 percent greater for the tested glasses than for those of BS 9940. Therefore, if the $N^{\prime}$ value of the nominal unit glass had been derived in the same manner and with the same values of $N$ as given in table 1 , but with glasses representative of the averages found for the tested glasses, this $N^{\prime}$ value would have approximated $1.173 / 1.027=1.142$, instead of the value 1.173 obtained from the 20 glasses of BS 9940. Equation 3 would, in this case, have been:

$$
\left(N^{\prime \prime}\right)=(1.02 / 1.027) N+0.14 / 1.027=0.993 N+0.14 .
$$

On the average the values of $N^{\prime \prime}$ and $N$ for the first 1,000 glasses would then have been more nearly alike for the larger values of $N$. 
For small values of $N$, however, this change in the unit would produce but little change in the values of $N^{\prime \prime}$. For this region, the observed differences between $N^{\prime \prime}$ and $N$ are due mostly to lack of additivity in the average $N$ scale, as exemplified by the intercepts of the equations, that is, the values of $N^{\prime \prime}$ when $N=0$. (See RP653, p. 279 to 282 .) No change in the magnitude of the unit would effect any appreciable improvement in this respect.

It is in no way surprising that the 20 glasses of the Bureau set, BS 9940, fail to give exactly the same scale and unit that a much larger number of glasses would have given. The slight failure of the Bureau glasses to be accurately representative of the first 1,000 glasses graded has apparently caused no trouble or inconvenience to the oil trade, whereas the elimination of the erratic and consistent deviations from additivity that existed among the Lovibond red glasses when combined with $35 \mathrm{Y}$ has removed one of the principal causes of dispute regarding the color grading of cottonseed oils. The Priest-Gibson $\left(N^{\prime \prime}\right)$ scale may now be considered as thoroughly established in America.

\section{APPENDIX}

\section{EFFECT OF SPECTROPHOTOMETRIC UNCERTAINTIES}

The question arises as to whether the differences between the values of $r / g$ obtained for the standards in 1930 and those obtained earlier (1924-28) are due to changes in the glasses or to errors in the determinations of their spectra transmissions. It is believed the latter is the cause, inasmuch as adequate reasons are known for the discrepancies. The differences in the two determina-1 tions of spectral transmission may be put into 2 classes:

1. Those caused by ordinary experimental error. It has previously been pointed out ${ }^{34}$ that the Lovibond glasses are imperfect optically. Striae, bubbles, and pits are usually present in varying degree and there is known to be in some cases a slight variation of color over the surface of the glass. For glasses of such optical condition, highly accurate measurements cannot be made, and errors or uncertainties as large as 1 percent of the transmission are to be expected. A total discrepancy of 2 percent between 2 determinations is, therefore, not considered excessive. This limit was rarely exceeded at any wave length for any of the 17 standards listed in table 3, excepting 1 glass, $N=9.0$, where a bubble in the center of the glass was apparently the cause of the earlier values averaging 3.0 percent lower than the later ones, and excepting the glasses, $N=12.0,13.0,17.0$, and 20.0 at 500 to $550 \mathrm{~m} \mu$, which are discussed below. It is quite certain that the recent determinations are more accurate than the previous ones; the spectrophotometric technique has been improved, and from 2 to 4 complete sets of measurements were made on each glass in the recent determination as compared to only 1 (in most cases) in the previous determinations.

2 . Those ascribed to special instrumental error. The glasses having values of $N=12.0$ to $N=20.0$ show consistent discrepancies in the region of maximum absorption, viz, from 500 to $550 \mathrm{~m} \mu$, the discrepancies increasing as $N$ increases. The earlier values were lower than the recent ones, thus causing the $r / g$ values to be higher. These relatively large discrepancies from 500 to $550 \mathrm{~m} \mu$ may be certainly ascribed to instrumental error in the 1923 measurements. The apparatus was at that time as described in BS Sci. Pap. S440. For the recent measurements, the apparatus was as described in BS Research Pap. RP30. Among other improvements was the installation of auxiliary rotating sectors of accurately known aperture. For low transmissions, where the nicol readings are otherwise too near the extinction points, a sector of 10 or 1-percent aperture is now used in the blank beam and the transmission of the glass measured relative to that of the sector. This brings the nicol readings back into a part of the scale known to be accurate by measurements made on sectors of higher transmission. ${ }^{35}$ These

\footnotetext{
${ }_{34}$ BS Sci. Pap. S547, p.14.

3s For further discussion and illustration of this point, see BS Research Pap. RP30; also J.O.S.A. 21, 564 (September 1931).
} 
auxiliary sectors were used at low transmissions in all the recent measurements, so that in the region of lowest transmission, 500 to $550 \mathrm{~m} \mu$, the discrepancies found should be due mostly to errors in the previous measurements.

\section{TABLE 5.-Differences in $r / g$ and $N^{\prime \prime}{ }_{r / o}$ caused by differences in spectral transmission obtained in 2 different determinations}

[A refers to first determination, B to second determination]

\begin{tabular}{|c|c|c|c|c|c|}
\hline$N$ & $(r / g)_{\mathrm{A}}-(r / g)_{\mathrm{B}}$ & $\Delta\left(N^{\prime \prime}{ }_{r / \sigma}\right)$ & $N$ & $(r / g)_{\mathrm{A}}-(r / g)_{\mathrm{B}}$ & $\Delta\left(N^{\prime \prime}{ }_{r / \sigma}\right)$ \\
\hline $\begin{array}{l}0.86 \\
1.8 \\
2.0^{b} \\
2.8 \\
3.9\end{array}$ & $\begin{array}{r}-0.0017 \\
-.0026 \\
+.0013 \\
+.0027 \\
-.0003\end{array}$ & $\begin{array}{r}-0.03 \\
-.05 \\
+.02 \\
+.02 \\
.00\end{array}$ & $\begin{array}{l}7.0^{a} \\
7.6^{2} \\
8.0^{a} \\
8.2 \\
9.0\end{array}$ & $\begin{array}{r}-0.0032 \\
+.0070 \\
+.0030 \\
+.0006 \\
+.0058\end{array}$ & $\begin{array}{r}-0.04 \\
+.09 \\
-.04 \\
.00 \\
+.07\end{array}$ \\
\hline $\begin{array}{l}4.0^{a} \\
4.0^{b} \\
4.9^{9} \\
5.0^{a} \\
5.4^{a}\end{array}$ & $\begin{array}{l}-.0029 \\
+.0004 \\
+.0010 \\
-.0048 \\
+.0024\end{array}$ & $\begin{array}{r}-.05 \\
.00 \\
+.01 \\
+.06 \\
+.03\end{array}$ & $\begin{array}{l}9.0^{a} \\
9.8^{-1} \\
10.0^{a} \\
10.0^{b} \\
12.0^{b}\end{array}$ & $\begin{array}{r}-.0052 \\
+.0044 \\
-.0047 \\
-.0053 \\
+.0120\end{array}$ & $\begin{array}{l}-.07 \\
+.05 \\
-.06 \\
-.06 \\
+.15\end{array}$ \\
\hline \multirow[t]{2}{*}{$\begin{array}{l}5.6 \\
6.0^{a} \\
6.0^{a} \\
6.0^{b} \\
6.8\end{array}$} & $\begin{array}{l}+.0001 \\
+.0046 \\
+.0022 \\
+.0030 \\
+.0041\end{array}$ & $\begin{array}{r}.00 \\
+.06 \\
+.03 \\
+.03 \\
+.05\end{array}$ & $\begin{array}{l}13.0 \\
17.0 \\
20.0 \\
20.0^{a}\end{array}$ & $\begin{array}{r}+.0149 \\
+.0247 \\
+.0254 \\
-.0244\end{array}$ & $\begin{array}{l}+.18 \\
+.33 \\
+.35 \\
-.33\end{array}$ \\
\hline & & & \multicolumn{2}{|c|}{ Arith. Mean $(N=0.86$ to 10.00$)=$} & 0.038 \\
\hline
\end{tabular}

a BS test 432-1;

$b$ BS test 59139 .

Other values, BS 9940.

In table 5 are shown the differences in $r / g$ obtained from the 2 sets of spectrophotometric measurements and the differences in $N^{\prime \prime}{ }_{r / 0}^{36}$ equivalent to these differences in $r / g$. These values are given not only for the standards of BS 9940 but also for certain other glasses upon which 2 complete sets of spectral transmission measurements had been made. Values of $\Delta\left(P-P_{N^{\prime \prime}}\right)$ in no case exceed \pm 0.0011 .

It seems apparent from table 5 that uncertainties in $N^{\prime \prime}{ }_{r / 0}$ resulting from our spectrophotometric data, for values of $N$ not greater than 10.0, are less than 0.1 . The average discrepancy is about 0.04 . We believe that possible errors in values of $N^{\prime \prime}{ }_{r / o}$ determined from present spectrophotometric data obtained in the colorimetry section will not exceed \pm 0.05 . Without due regard to the various considerations necessary to insure accurate spectrophotometric work, however, considerably larger errors than those illustrated may result. The four glasses of BS test 59,139, table 5, were measured in another laboratory. The following discrepancies were obtained between values computed from their published curves, subscript $\mathbf{C}$, and from our second determinations:

\begin{tabular}{|c|c|c|}
\hline$N$ & $(r / g)_{C}-(r / g)_{B}$ & $\Delta\left(N^{\prime \prime}{ }_{r / \sigma}\right)$ \\
\hline $\begin{array}{r}2.0 \\
4.0 \\
6.0 \\
10.0\end{array}$ & $\begin{array}{r}-0.0005 \\
+.0073 \\
+.0225 \\
+.0425\end{array}$ & $\begin{array}{l}-0.01 \\
+.11 \\
+.31 \\
+.54\end{array}$ \\
\hline
\end{tabular}

These values compared with those for the same glasses in table 5 show the relatively large errors that may be obtained from inaccurate spectrophotometric measurements.

The question arises also as to why the $N^{\prime \prime}{ }_{r / 0}$ values originally obtained for the glasses of BS 9940 (having values of $N=1.0,2.0,3.0, \ldots 20.0$ ) in the derivation of the Priest-Gibson scale in table 1 are additive, as shown by the revised

36 It should be remembered that the value of $N^{\prime \prime}{ }_{r / a}$ was not changed for any of the standard glasses (see section V); the values of $\Delta N^{\prime \prime} r / g$ in the case of the standards merely show the differences in $N^{\prime \prime} r_{/ g}$ that are equivalent to the differences in $r / g$ obtained in the 2 determinations. 
curve of figure 3 , when the higher valued glasses have been found to have significant errors in the original spectral transmission measurements. The answer seems to be that these errors were more or less consistent and caused errors in the values of $r / g$ which were roughly proportional to $N$. This is shown in figure 4 where the values of $(r / g)_{A}-(r / g)_{B}$ (table 5) are plotted for those glasses of BS 9940 which entered into the derivation of the scale in table 1 , viz., $N=6.0,9.0$, $12.0,13.0,17.0$, and 20.0. A straight line drawn through these values intersects the abscissa at $N=5.0$ approximately instead of $N=0$; however, the rough

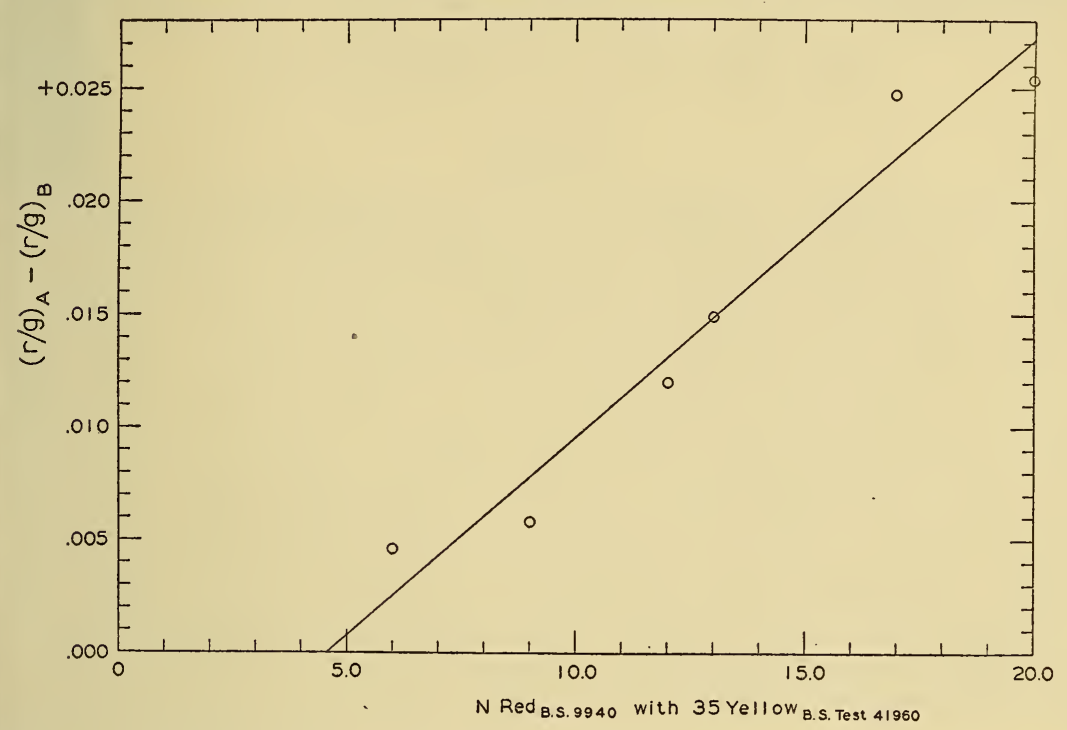

FIgURE 4.-Relation between values of $N$ and the discrepancies in $\mathrm{r} / \mathrm{g}$ for certain glasses of BS 9940 .

proportionality shown for values of $N$ greater than 5.0 is believed to afford adequate explanation of the question raised at the beginning of this section, since the $r / g$ curve is nearly straight between $N^{\prime \prime}=5.0$ and $N^{\prime \prime}=20.0$. It is interesting to note that the revised curve in figure 3 deviates from the original curve only for values of $N^{\prime \prime}$ greater than 5.0.

Washington, June 26, 1934. 